\title{
DESIGN OF WIDE BAND MICROSTRIP ARRAY ANTENNA USING DIRECT COUPLED TECHNIQUE
}

\author{
B G Dinesh $^{1}$, S L Mallikarjun ${ }^{2}$, P M Hadalgi ${ }^{3}$, P V Hunagund ${ }^{4}$ \\ ${ }^{I}$ Research Student, Dept. of Applied Electronics, Gulbarga University, Gulbarga, Karnataka, India. \\ ${ }^{2}$ Guest Faculty, Dept. of Applied Electronics, Gulbarga University, Gulbarga, Karnataka, India. \\ ${ }^{3}$ Professor, Dept. of Applied Electronics, Gulbarga University, Gulbarga, Karnataka, India. \\ ${ }^{4}$ Professor, Dept. of Applied Electronics, Gulbarga University, Gulbarga, Karnataka, India.
}

\begin{abstract}
The article presents the design of a linearly polarized non-radiating edge directly coupled microstrip array antenna for X-band applications. The array elements are excited by corporate feed network, which enhances the impedance bandwidth of the two element non-radiating edge directly coupled rectangular microstrip array antenna (TNDRMAA) by $30.12 \%$. The measured results for array antennas in term of reflection coefficient, radiation pattern, half power beam width (HPBW) and gain are presented.
\end{abstract}

Keywords: Microstrip array antenna, Dual band, Direct-coupling, Corporate feed.

****

\section{INTRODUCTION}

In various wireless communication systems, there is a necessity for low-profile and light weight antennas. These antennas are minimum conspicuous than conventionally used parabolic reflectors. In addition, wind, rain or snow has less affect on their performance. [1] Microstrip antenna elements radiate efficiently as devices on printed circuit boards. Microstrip array antenna involves microstrip antenna elements, phasing networks and feed. Constructing a microstrip structure requires understanding of both mathematical relatives and applications [2]. An array antenna is very reliable since the entire array is one continuous piece of copper.

The predictable effort has been made to the design of feed network which aims at division of power from input port to patch element with the ideal match at any level within the network up to the radiating patch element. This patch impedance bandwidth is known to depend on the thickness of substrate. Conventional impedance bandwidth enhancement approaches intend at broadening the bandwidth by using multilayer construction using parasitic elements and electromagnetic coupling or by employing a matching filter network attached to each element and next the approach is to require additional circuit area for every patch element, which often is in argument with the desirable circuit area for the feed network. [3] The very accepted choice is a corporate feed network; in which two-way power dividers are given in a rectangular matrix. [4]

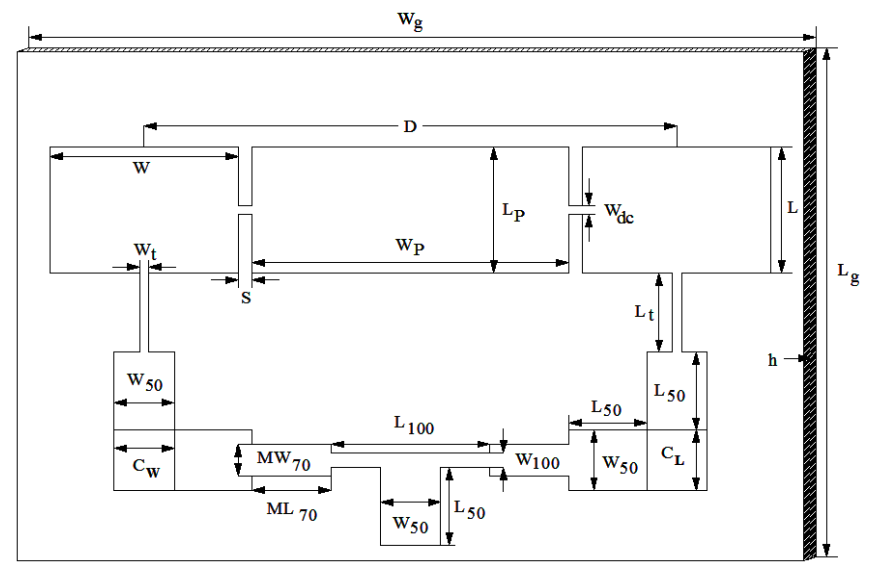

Fig-1 Geometry of TNDRMAA

\section{DESIGN SPECIFICATIONS}

In the present study antennas are designed using glass epoxy substrate material which is of low cost and the dielectric constant $\varepsilon_{r}=4.2$ and thickness $h=1.6 \mathrm{~mm}$. The geometry of two element non-radiating edge directly coupled rectangular microstrip array antenna (TNDRMAA) is shown in Figure 1.

The radiating elements of array are designed for the frequency of $9.4 \mathrm{GHz}$ with dimensions $L=6.6 \mathrm{~mm}$ and $W=9.9 \mathrm{~mm}$. As the radiation pattern of the proposed antenna is measured with the help of bench and in bench it is observed that the microwave source i.e. Gunn oscillator starts to give more power from $9.4 \mathrm{GHz}$, hence we have taken $9.4 \mathrm{GHz}$ as the design frequency. An optimized non-radiating element of dimension of length, $L_{P}=6.6 \mathrm{~mm}$ and width, $W_{P}=17.2 \mathrm{~mm}$ is 
placed between the radiating elements, which forms the nonradiating edge which is direct-coupled. The distance between the parasitic and radiating element $S$ is optimized and is taken as $0.025 \lambda_{g}$, where $\lambda_{g}$ is the operating wavelength in $\mathrm{mm}$ [5]. The direct coupling is done through a coupler with width $W_{d c}$ $=0.4 \mathrm{~mm}$ and it is an optimized dimension. The length will be same as $S$. Length $L_{g}=48.2 \mathrm{~mm}$ and width $W_{g}=50.5 \mathrm{~mm}$ of the ground plane of antenna is measured using the equations; $L g=6 h+L$ and $W g=6 h+W[6]$. Elements of this array antenna are connected through a corporate feed arrangement. This consists of matching transformer, coupler, quarter wave transformer and power divider for better impedance matching between feed and radiating patch [7].

A two-way power divider of $100 \Omega$ of dimension $L_{100}=8.3$, $W_{100}=0.7 \mathrm{~mm}$ is used between impedances of $70 \Omega$ matching transformer of measurements $M L_{70}=4.1, M W_{70}=1.6 \mathrm{~mm}$ and $50 \Omega$ of dimension $L_{50}=4.1, W_{50}=3.1 \mathrm{~mm}$. A coupler of dimension $C_{L}=C_{W}=3.1 \mathrm{~mm}$ is used between $50 \Omega$ microstrip lines to divide the power $[8,9]$. The $50 \Omega$ microstrip line is connected at the centre of the driven element through a quarter wave transformer of dimension $L_{t}=4.1, W_{t}=0.4 \mathrm{~mm}$ for good impedance matching. At the tip of microstrip line feed of 50 $\Omega$, a coaxial SMA connector is used for feeding the microwave power. The radiating array elements are kept at a distance of $D=27.9 \mathrm{~mm}$ from their centre point. This optimized distance is chosen in order to attain lower side lobes in the radiation pattern and to add the radiated power in free space [10].

\section{EXPERIMENTAL RESULTS AND DISCUSSION}

Impedance bandwidth of the proposed antenna is measured. The measurements are taken on Vector Network Analyzer. The graph of reflection coefficient versus frequency of TNDRMAA is shown in Figure 2.

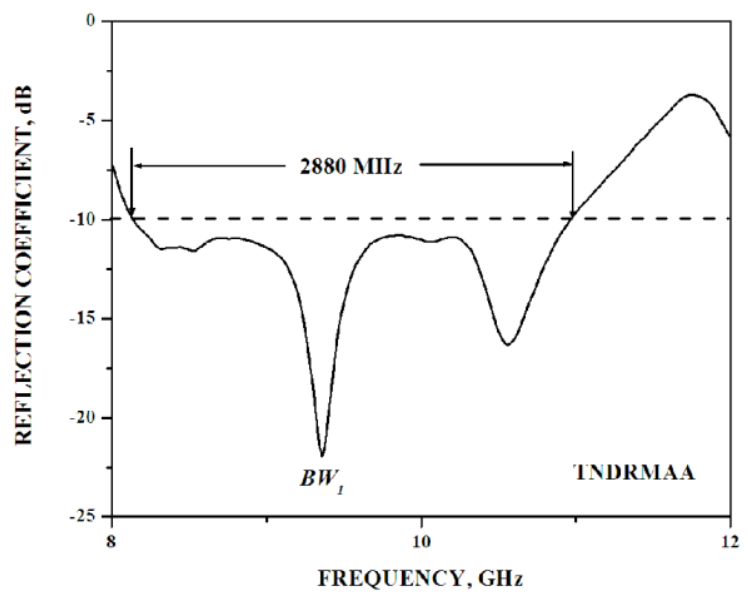

Fig- 2: Graph of reflection coefficient versus frequency

From figure 2, it is observed that TNDRMAA offers single wide band at $9.36 \mathrm{GHz}$, with a magnitude of $2880 \mathrm{MHz}$
(30.12\%) which is 9.81 times more as compared to single radiating element $(3.07 \%)$ and 1.95 times more when compared to the experimental impedance bandwidth of 2RMSAA. [11] Also the minimum reflection coefficient calculated in this antenna is found to be $-21.95 \mathrm{~dB}$. This enhancement in impedance bandwidth is because of combined resonance of the elements fed by corporate feed network. [12]

The H-plane co-polarization and cross-polarization radiation pattern of the antenna is measured at the resonating frequency and is shown in figures 3 . It is clear from the figure, that the antenna is showing a radiation characteristic of broad side in nature with lower cross polarization level. The radiation pattern of TNDRMAA is measured at $9.36 \mathrm{GHz}$.

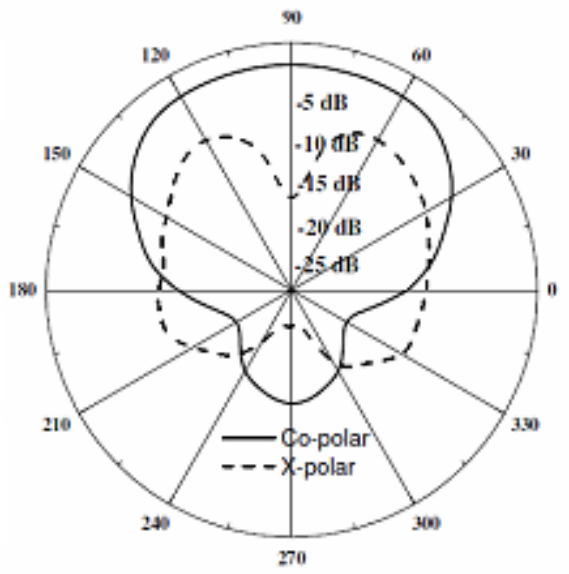

Fig 3: Radiation pattern at $9.36 \mathrm{GHz}$.

HPBW of antenna is found to be $106^{\circ}$. Further, to find the gain, the power transmitted $\left(P_{t}\right)$ by the pyramidal horn antenna and the power received $\left(P_{s}\right)$ by proposed antenna is measured separately. Gain of antenna under test $\left(G_{T}\right)$ in $\mathrm{dB}$ is calculated using the formula:

$$
\left(G_{T}\right) d B=(G s) d B+10 \log \left(P_{t} / P_{s}\right)
$$

Where Gs is the gain of pyramidal horn antenna. From the analysis the obtained gain is about $7.30 \mathrm{~dB}$. When compared to conventional rectangular microstrip antenna, the gain of TNDRMAA has improved. This shows that gain of the antenna can be improved by direct-coupling and array configuration.

TNDRMAA is showing a wide band application. The Smith chart of TNDRMAA is shown in figure 4 . From the figure, it is seen that the input impedance has a loci at the center of Smith chart which confirms its wide band operation. 


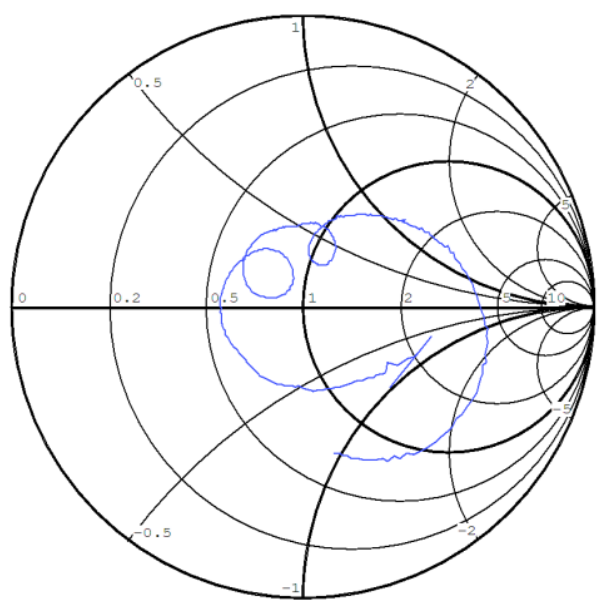

Fig 4: Smith chart profile

\section{CONCLUSIONS}

This experimental study shows that the antenna is relatively easy in design and fabrication and quite good in increasing the impedance bandwidth and give better gain with broadside radiation pattern at the resonating frequency. This antenna is also superior as it uses single layer low cost substrate material and find applications in modern communication system, microwave wireless communication system and in radar communication systems.

\section{REFERENCES}

[1]. Hyok Song J \& Marek Bialkowski E, "Ku-Band $16 \times 16$ planer array with aperture-coupled microstrip patch elements", IEEE Antennas Propag. Mag. (USA), (40), 25, 1998.

[2]. Ramesh G, Bhartia P, "Microstrip Antenna design Handbook", Artech House, 2000.

[3]. Solbach K \& Litschke O, Patch-array-antenna feed network providing bandwidth improvement, University of Duisburg, Essen, 2005.

[4]. Munson Robert E, "Conformal microstrip antennas and microstrip phased arrays", IEEE Trans. Antennas Propag. (USA), (12), 74, 1974.

[5]. Girish Kumar and Ray K P, Broadband Microstrip Antennas, Artech House, London, pp. 89-110, 2003.

[6]. Bhal I J and Bhartia P, Microstrip Antennas, Artech House, New Delhi, pp. 230-234, 1980.

[7]. Kai Fong Lee, \& Weichen, Advances in Microstrip and Printed Antennas, John Wiley, New York, 1997.

[8]. Oing X M and Chia Y W M, "Circularly Polarized Circular Ring Slot Antenna Fed by Stripline Hybrid Coupler", Elect. Lett., Vol. 35, pp. 2154-2155, 1999.

[9]. Jong Kim I I and Young Joong Yoon, "Design of Wideband Microstrip Array Antenna Using the Coupled Lines", in IEEE Antenna and Prop. Soci. Int. Symp., No. 3, pp. 1410-1413, 2000.

[10]. Constantine Balanies A and Antenna, Theory Analysis and Design, John Wiley \& Sons Inc., New York, 1982.
[11]. Mallikarjun S L, Madhuri R G, Malipatil S A and Hadalgi P M, "Development of micostrip array antenna for wide band and multiband applications", Indian Journal of Radio \& Space Physics, Vol. 38, pp289-294, 2009.

[12]. Hadalgi P M and Mallikarjun S L, "Design \& Development of Microstrip Array Antenna with Broader Bandwidth and Beam", Int. Journal of Electronics Engineering, Vol. 1, No. 2, pp. 251-253, 2009. 